\title{
A Wider Range of Conditions Contributing to Death in a Cohort of People Who Have Injected Drugs. Findings from an Edinburgh Cohort.
}

Roy Robertson ( $\sim$ Roy.Robertson@ed.ac.uk)

University of Edinburgh https://orcid.org/0000-0001-8237-816X

Lorraine Copeland

Muirhouse Medical Group

James McKenzie

Muirhouse Medical Group

\section{Research}

Keywords: Drug deaths, Injecting drug use, Mortality, Inequalities

Posted Date: November 13th, 2020

DOl: https://doi.org/10.21203/rs.3.rs-105199/v1

License: (c) (i) This work is licensed under a Creative Commons Attribution 4.0 International License.

Read Full License 


\section{Abstract}

\section{Background}

The morbidity and mortality attributed to injecting drug use is a substantial contributor to any study on causes of premature death. Understanding the extent of this may be limited by difficulties in observing and recording outcomes over several decades. Historic studies have recorded information in a period when blood borne virus and drug deaths were a smaller proportion or, in the cases of Hepatitis $\mathrm{C}$ and HIV/AIDS, absent from National mortality figures.

\section{Design and setting}

A cohort of people who had, ever, injected drugs was established over a prolonged period of observation in one, community based, medical practice in Edinburgh (UK). Outcomes were measured in the clinical situation and by accessing death certificates from national, UK, registers.

\section{Findings}

Causes of death in a cohort of 794 people who inject drugs (PWIDs) varied over time, some conditions relating to single pathological diagnoses and others were more complicated, multimorbid, and cumulative over time. HIV/AIDS was a striking cause of death until 1995 when antiviral chemotherapy was introduced. Drug related deaths (mainly overdose) remained a significant cause of death and death due to alcohol, respiratory, cardiovascular and cancer (mainly lung) increased over time. A wide range of other causes including suicide and violence and trauma were recorded.

\section{Conclusions}

Mortality resulting from present or historic drug use may be underestimated in current recoding systems, which largely record deaths from overdose or a single pathological event in an acute situation. The range of conditions causing or contributing to premature death is enormous reflecting multiple risks associated with drug use.

\section{Background}

Over the last 40 years cohort studies have reported on survival and outcomes for people who have injected drugs (1-4). These studies record various morbid processes and events causing death, the most common over time being opiate poisoning, often by accidental overdose. Official statistics in the UK usually relate to overdose and problems of definition of what constitutes a drug related death are acknowledged as well as the inconsistency between countries. $(5,6)$. Deaths from other causes are often obscured either because no opiates were present when the final event occurred, the person died of apparently unrelated cause or past drug use was unknown by the recoding medical attendant. Attempts have been made to describe this, larger, group and to attribute causation to comorbid drug use $(1,7-12)$. Injecting drugs causes more harm than other modes of use and consequently many studies have 
concentrated on this group rather than the less well defined people who use drugs without injecting. This study presents a wider view of drug related mortality, the data recording all causes many of which were generated directly by injecting drugs.

\section{Methods}

People who had ever injected an illegal drug were recoded in a large community NHS practice by searching the caseload for drug dependence and injecting drug use. From 1984 until 2015 various studies were conducted each requiring separate consent and ethical approval (13-16). Prospectively participants were "flagged" at the National Records Office for Scotland and ethical permission to use these data for this study was again granted in 2019 (below).

Information retrieved from national records were anonymised and data presented is from death certificates.

\section{Results}

There were 794 people who had at some time in their lives injected drugs in the cohort (Table 1). The age range at first injection was wide (11-38 years, mean 19.64, for those who had died compared to 1239 years mean 20.02 for those who did not die) as was age at recruitment (16-54 years for those dead and 16-52 for those still alive). Years of follow up ranged from less than 1 to 34 (mean 12.50) and years from first injection less than 1 to 53 (mean 20.86).

Table 1

CHARACTERISTICS OF THE EAC COHORT

\begin{tabular}{|llllll|}
\hline & *N & Minimum & Maximum & Mean & Std. Deviation \\
\hline Age first injected (dead cases) & 326 & 11 & 38 & 19.64 & 5.01 \\
\hline Age first injected (live cases) & 367 & 12 & 39 & 20.02 & 4.39 \\
\hline Age recruited (dead cases) & 357 & 16 & 54 & 26.92 & 6.53 \\
\hline Age recruited (live cases) & 432 & 16 & 52 & 26.58 & 6.31 \\
\hline Years follow up (dead cases) & 356 & $<1$ & 34 & 12.50 & 8.26 \\
\hline Years first injected until death & 341 & $<1$ & 53 & 20.86 & 10.15 \\
\hline Age at death & 359 & 16 & 68 & 39.31 & 9.69 \\
\hline *number where data is available & & & & & \\
\hline
\end{tabular}

Age at death ranged from 16-68 (mean 39.31) 
Age of recruitment, years of follow up, and age at death were similar for men and women (Table 2).

Table 2

Male and female characteristics

\begin{tabular}{|c|c|c|c|c|c|c|}
\hline Gender & & $* N$ & Minimum & Maximum & Mean & $\begin{array}{l}\text { Std. } \\
\text { Deviation }\end{array}$ \\
\hline \multirow[t]{7}{*}{ Males } & $\begin{array}{l}\text { Age first injected (dead } \\
\text { cases) }\end{array}$ & 234 & 11 & 38 & 19.48 & 5.10 \\
\hline & Age first injected (live cases) & 232 & 12 & 33 & 19.91 & 4.17 \\
\hline & Age recruited (dead cases) & 259 & 16 & 54 & 27.09 & 6.69 \\
\hline & Age recruited (live cases) & 279 & 16 & 48 & 26.87 & 6.16 \\
\hline & Years follow up (dead cases) & 258 & $<1$ & 33 & 12.49 & 8.36 \\
\hline & Years first injected until death & 243 & 1 & 53 & 21.15 & 10.14 \\
\hline & Age at death & 261 & 16 & 68 & 39.44 & 9.52 \\
\hline \multirow[t]{7}{*}{ Females } & $\begin{array}{l}\text { Age first injected (dead } \\
\text { cases) }\end{array}$ & 92 & 13 & 38 & 20.04 & 4.78 \\
\hline & Age first injected (live cases) & 133 & 13 & 39 & 20.21 & 4.76 \\
\hline & Age recruited (dead cases) & 98 & 17 & 42 & 26.45 & 6.09 \\
\hline & Age recruited (live cases) & 153 & 16 & 52 & 26.07 & 6.55 \\
\hline & Years follow up (dead cases) & 98 & $<1$ & 34 & 12.54 & 8.02 \\
\hline & Years first injected until death & 98 & 2 & 48 & 20.15 & 10.18 \\
\hline & Age at death & 98 & 20 & 66 & 38.97 & 10.19 \\
\hline
\end{tabular}

Causes of death are those identified by the certifying physician as directly relating to the fatal outcome. Causes listed in Table 3 are additional entries on the death certificate and refer to conditions present at the time of death but not necessarily contributing to the death in the judgement of the certifying doctor. 
Table 3

Diagnoses included on certificates but not given as primary reason for death

\begin{tabular}{|c|c|c|}
\hline Acute alcohol intoxication & $\begin{array}{l}\text { Fall from height, multiple } \\
\text { injuries (mental depression, } \\
\text { chronic drug abuse) }\end{array}$ & $\begin{array}{l}\text { Paracetamol intoxication (coded } \\
\text { as intentional self-harm in ICD) }\end{array}$ \\
\hline AIDS & $\begin{array}{l}\text { Fatal alcohol, diazepam, } \\
\text { morphine and hydrocodeine } \\
\text { poisoning }\end{array}$ & $\begin{array}{l}\text { Progressive multifocal } \\
\text { leukoencephalopathy }\end{array}$ \\
\hline Alcoholic liver disease & $\begin{array}{l}\text { Fatal poisoning with } \\
\text { methadone, alcohol and } \\
\text { diazepam }\end{array}$ & Pulmonary embolism \\
\hline Amitriptyline overdose & $\begin{array}{l}\text { Fatal toxicity with methadone } \\
\text { and fluoxetine }\end{array}$ & Renal failure \\
\hline Ascending cholangitis & $\begin{array}{l}\text { Fatty liver (chronic drug and } \\
\text { alcohol abuse) }\end{array}$ & $\begin{array}{l}\text { Right middle cerebral artery } \\
\text { aneurysm }\end{array}$ \\
\hline B-cell lymphoma & Gastrointestinal bleeding & Schizophrenia, renal failure \\
\hline $\begin{array}{l}\text { Bowel ischemia resulting in } \\
\text { cardiac arrest }\end{array}$ & $\begin{array}{l}\text { Glioblastoma, hepatocellular } \\
\text { carcinoma }\end{array}$ & $\begin{array}{l}\text { Self injection with crushed tablets, } \\
\text { extensive clostridium perfringens } \\
\text { infection }\end{array}$ \\
\hline Brain abscess & $\begin{array}{l}\text { Haematemesis with lung } \\
\text { aspiration }\end{array}$ & Self-strangulation by ligature \\
\hline Bronchopneumonia & Hanging & Septicaemia \\
\hline $\begin{array}{l}\text { Carbon monoxide } \\
\text { poisoning }\end{array}$ & $\begin{array}{l}\text { Head injury from road traffic } \\
\text { incident }\end{array}$ & Severe hydrocephalus \\
\hline $\begin{array}{l}\text { Carcinoma of liver, } \\
\text { Hepatitis C }\end{array}$ & Hepatic cirrhosis & Squamous carcinoma of lung \\
\hline Carcinoma of tonsil & Hepatitis C & Stab wounds of chest \\
\hline $\begin{array}{l}\text { Cardiac enlargement } \\
\text { associated with coronary } \\
\text { artery atheroma }\end{array}$ & $\begin{array}{l}\text { Hepatitis C and alcoholic liver } \\
\text { disease }\end{array}$ & Staphylococcal septic shock \\
\hline Cardiomegaly & $\begin{array}{l}\text { Hepatitis C, hepatitis B, hepatic } \\
\text { cirrhosis }\end{array}$ & $\begin{array}{l}\text { Sudden death in epilepsy } \\
\text { syndrome }\end{array}$ \\
\hline Cerebral lymphoma & Heroin addiction & Tuberculosis \\
\hline Cerebral neoplasm & HIV & Valvular heart disease \\
\hline Cerebral toxoplasmosis & Hodgkins Lymphoma & Variceal bleed \\
\hline $\begin{array}{l}\text { Chest and abdominal } \\
\text { trauma (impact with a } \\
\text { falling tree) }\end{array}$ & Hypoxic brain injury & Viral encephalopathy \\
\hline Chest infection & Intra cerebral haemorrhage & \\
\hline
\end{tabular}




\begin{tabular}{|lll|}
\hline Acute alcohol intoxication & $\begin{array}{l}\text { Fall from height, multiple } \\
\text { injuries (mental depression, } \\
\text { chronic drug abuse) }\end{array}$ & $\begin{array}{l}\text { Paracetamol intoxication (coded } \\
\text { as intentional self-harm in ICD) }\end{array}$ \\
\hline Chronic alcoholism & $\begin{array}{l}\text { Ischaemic bowel; multi organ } \\
\text { failure }\end{array}$ \\
\hline Chronic hepatitis B and C & Ischaemic heart disease \\
\hline Chronic renal failure & Liver cirrhosis \\
\hline $\begin{array}{l}\text { Chronic viral hepatitis B } \\
\text { infection }\end{array}$ & Lobar pneumonia, infection with \\
\hline Cirrhosis of the liver & Lower respiratory tract infection \\
\hline
\end{tabular}

The HIV/AIDS was the single most frequent diagnosis followed by overdose. Other conditions causing death were cardiovascular, respiratory and malignant diseases with smaller but significant mortality attributed to suicide, alcohol, violence and trauma.

\section{Conclusions}

There are many issues constraining a clear view of the outcomes of drug use. Causes of death varied over time, most strikingly with the introduction of HIV infection into the cohort and the dramatic effect of antiviral chemotherapy in the middle of the 1990 decade (Fig. 1).

Other trends reflect the long incubation period of hepatitis $C$ which was introduced into the cohort in the early 1980's when injecting first emerged in this population of, then, young people and the increase in drug related, liver and cardiovascular and respiratory causes of death.

The range of other conditions recorded on death certificates in this group is enormous and some are not directly related to drug injecting (Table 3).

Scrutiny of this extensive list illustrates the collateral damage often evident in caseloads attending drug treatment centres. Many, if not most, of these co existing conditions at the time of death are seen to be related to a lifestyle associated with poverty, inequalities, and drug use.

Drug use over a lifetime is, for most, an intermittent problem rather than following a linear pattern. Drug use and associated risks are often intermittent following a pattern of relapse and remission (17). There is an acute risk of, one off, hazards such as overdose, infection with a blood borne virus or a vascular event but there is also a cumulative risk over time resulting in premature fatal or morbid events.

Drug use is sometimes a poorly defined entity with many manifestations some more serious than others and some, like injecting behaviours, with the potential for immediate risk of death. Research often concentrates on short term problems and outcomes of treatment interventions and the impact of 
treatments such as agonist prescriptions, detoxification episodes and residential rehabilitation may not be immediate and therefore are more complicated to measure.

Recorded numbers of drug related deaths reported in the UK and Europe are largely about overdoses and take little account of the larger spectrum of mortality which should be attributed to drug related causes. Current definitions of a drug related death, in the UK, depend upon the presence of a drug, controlled under the Misuse of Drugs Act 1971, to be present at the time of death. The impact of blood borne viruses and bacterial infections as well as the longer term outcomes from conditions connected to current or past drug use remain absent from totals of death from drug causes.

This study suggests that there are several deaths attributed to drug injecting for every one that is recorded as an overdose. The delayed impact of infection with a blood borne virus or long term drug use has been missing from many studies but needs to be considered when assessing the burden of disease in this population.

Drug policy is often ideologically based and highly political in its construction. Evidence influences approaches to treatment and prevention only in response to crises and when damage cannot be ignored (18). Primary care and community based facilities are the ideal opportunity to engage and retain contact with people who have long term drug related issues and provides the possibility of a range of interventions including, but well beyond, the prescribing of Medically Assisted Opiate Agonist treatment.

The outcome of drug taking and the continuation or abstinence from illegal drugs is covered elsewhere in this cohort series but at the time of death and in the surviving group many continue to use a mixed economy of drugs, some prescribed and some accessed elsewhere. As in other studies the comorbid use of cigarettes and alcohol is common.

\section{Strengths of this study}

This study overcomes the issues of under classification of drug related deaths to an extent as it is a population based sample of people mainly recruited quite early in their lives and drug using careers and followed up in multiple ways. It therefore allows a clearer and more complete picture of the true population costs of drug use to be seen - and they are substantial over a life course - probably as substantial as the costs of other things we hear more about, like obesity and lack of exercise or poor diet. But like all those things the damage is intrinsically linked to and exacerbated by deprivation. This study is the first to systematically access death certificates in a cohort of people who have injected drugs. Drug users are sometimes difficult to define but the inclusion of a single group identified by the characteristic of injecting drugs gives a clear picture of a group of people with, arguably, the most serious risk factor associated with drug use. The study has the advantage of following a group over time and identifying a changing pattern of disease caused by drug policy, emergence of new diseases and the effect of drugs over a long time period. Whereas many previous studies quantify mortality to mainly overdoses of drugs this study adds a clearer, more complete, picture of the multisystem damage. The unique nature of the 
point in time when HIV entered the drug using culture distinguishes this cohort from others over the past 4 decades of drug use in the UK.

\section{Weaknesses of this study}

A cohort from one locality clearly has limited generalizability and must be interpreted in context of local and national variation in treatment policy. Not all patients were recruited at the same time and therefore their risks of death from time dependent variables such as HIV/AIDS and drug policy evolution differs. The variation in length of time spent injecting drugs was large some individuals injecting for a short period and others consistently over many years. All were included as risks such as blood borne virus transmission can occur during a single injecting event.

\section{Declarations}

\section{Ethical approval and consent to participate.}

Ethical approval was obtained from the West of Scotland ethics committee. REC reference: 20/WS/0008. Protocol number: AC19108. IRAS project ID: 272287

Consent to the studies conducted in this long running cohort study was granted for each project and is included in the papers published (and cited in this paper). Consent was not considered to be required again for this study when it was granted (above) as no named patient data was included.

\section{Availability of data and materials}

All data generated or analysed during this study are included in this article.

\section{Competing interests}

The authors declare that they have no competing interests.

\section{Funding}

Funding at various stages in the long gestation of this project included grants from the Scottish Home and Health Department the Chief Scientist Office of the Scottish Government, The Scientific Foundation Board of the Royal College of General Practitioners, The Medical Research Council

\section{Authors contributions}

The data preparation was the responsibility of CP and JRR. Clinical interpretation was by JRR and JM and all authors contributed to the preparation of the paper.

\section{Acknowledgements}


There have been multiple collaborators over the years, many recognised in the reference section. The Partners and staff of the Muirhouse Medical Group have shown extraordinary professional commitment to a complex caseload. People with drug problems have taught us a lot and have endured less than perfect care during the process of learning about their condition.

\section{References}

1. Degenhardt L, Bucello C, Mathers B, Briegleb C, Ali H, Hickman M, et al. Mortality among regular or dependent users of heroin and other opioids: a systematic review and meta-analysis of cohort studies. Addiction. 2011;106(1):32-51.

2. Hser YI, Hoffman V, Grella CE, Anglin MD. A 33-year follow-up of narcotics addicts. Arch Gen Psychiatry. 2001;58(5):503-8.

3. Oppenheimer E, Tobutt C, Taylor C, Andrew T. Death and survival in a cohort of heroin addicts from London clinics: a 22-year follow-up study. Addiction. 1994;89(10):1299-308.

4. Vaillant GE. A 20-year follow-up of New York narcotic addicts. Archives of general psychiatry. 1973;29(2):237-41.

5. Corkery J. UK drug-related mortality - issues in definition and classification. Drugs and Alcohol Today. 2008;8:17-25.

6. Drugs ACotMo. Reducing Drug Related Deaths: A Report by the Advisory Council on the Misuse of Drugs: Stationery Office London; 2000.

7. Mathers BM, Degenhardt L, Bucello C, Lemon J, Wiessing L, Hickman M. Mortality among people who inject drugs: a systematic review and meta-analysis. Bull World Health Organ. 2013;91(2):10223.

8. Nambiar D, Agius PA, Stoové M, Hickman M, Dietze P. Mortality in the Melbourne injecting drug user cohort study (MIX). Harm Reduction Journal. 2015;12(1):55.

9. Paulozzi LJ, Xi Y. Recent changes in drug poisoning mortality in the United States by urban-rural status and by drug type. Pharmacoepidemiology and Drug Safety. 2008;17(10):997-1005.

10. Copeland L, Budd J, Robertson JR, Elton RA. Changing patterns in causes of death in a cohort of injecting drug users, 1980-2001. Arch Intern Med. 2004;164(11):1214-20.

11. Gao L, Robertson JR, Bird SM. Non drug-related and opioid-specific causes of 3262 deaths in Scotland's methadone-prescription clients, 2009-2015. Drug and Alcohol Dependence. 2019;197:262-70.

12. Bird SM, Robertson JR. Older-age opioid-related deaths in the UK. Lancet. 2020;396(10244):94-5.

13. Kimber J, Copeland L, Hickman M, Macleod J, McKenzie J, De Angelis D, et al. Survival and cessation in injecting drug users: prospective observational study of outcomes and effect of opiate substitution treatment. BMJ. 2010;341:c3172.

14. Robertson JR, Ronald PJ, Raab GM, Ross AJ, Parpia T. Deaths, HIV infection, abstinence, and other outcomes in a cohort of injecting drug users followed up for 10 years. BMJ (Clinical research ed). 
1994;309(6951):369-72.

15. Skidmore CA, Robertson JR, Robertson AA, Elton RA. After the epidemic: follow up study of HIV seroprevalence and changing patterns of drug use. Bmj. 1990;300(6719):219-23.

16. Macleod J, Copeland L, Hickman M, McKenzie J, Kimber J, De Angelis D, et al. The Edinburgh Addiction Cohort: recruitment and follow-up of a primary care based sample of injection drug users and non drug-injecting controls. BMC Public Health. 2010;10(1):101.

17. Xia Y, Seaman S, Hickman M, Macleod J, Robertson R, Copeland L, et al. Factors affecting repeated cessations of injecting drug use and relapses during the entire injecting career among the Edinburgh Addiction Cohort. Drug and Alcohol Dependence. 2015;151:76-83.

18. Kalk NJ, Robertson JR, Kidd B, Day E, Kelleher MJ, Gilvarry E, et al. Treatment and Intervention for Opiate Dependence in the United Kingdom: Lessons from Triumph and Failure. European Journal on Criminal Policy and Research. 2018;24(2):183-200.

\section{Figures}

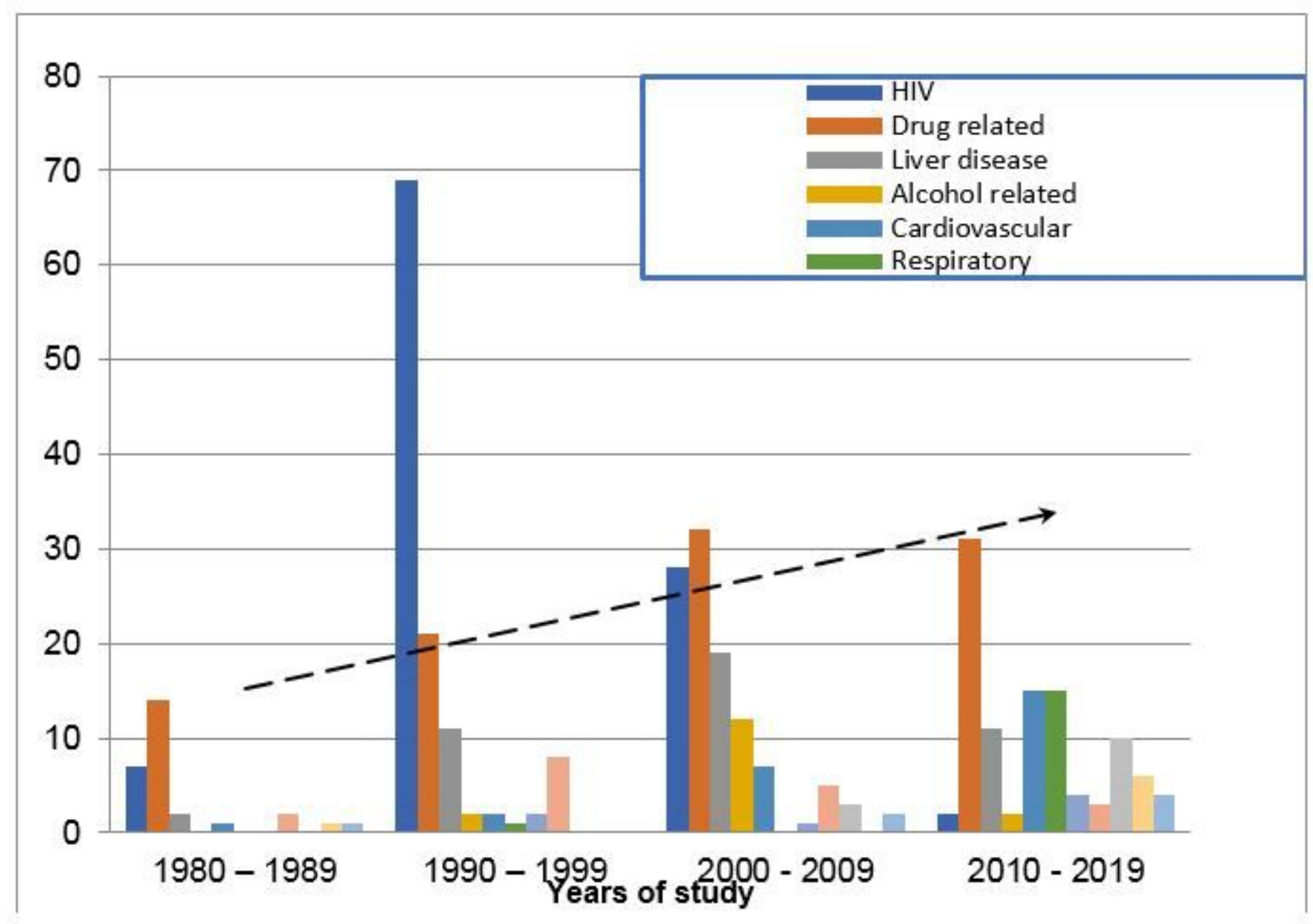

Figure 1 
Causes of death in the cohort, with trend line for drug related causes 